\title{
Effects of water environment on tribological properties of DLC rubbed against brass
}

\author{
Michimasa UCHIDATE ${ }^{\mathrm{a}, *}$, Haibo LIU ${ }^{\mathrm{a}}$, Akira IWABUCHI ${ }^{\mathrm{a}}$, \\ and Kenji YAMAMOTO ${ }^{b}$ \\ ${ }^{\mathrm{a}}$ Department of Mechanical Engineering, Iwate University, Ueda 4-3-5, Morioka-shi, Iwate, \\ 020-8551, Japan \\ ${ }^{\mathrm{b}}$ Materials Research Laboratory, Kobe Steel Ltd., 5-5, Takatsukadai 1-chome, Nishi-ku, Kobe \\ 651-2271, Japan \\ *Corresponding author (E-mail: uchidate@iwate-u.ac.jp)
}

\begin{abstract}
The effects of the water environment, such as temperature, dissolved ions, dissolved oxygen etc., on the tribological properties of diamond-like carbon (DLC) against brass were studied as part of the development of water-lubricated hydraulics, valves and cylinders based on metals (Fe alloys, $\mathrm{Cu}$ alloys etc.). A ball-on-disk type tribotester was used to examine the above various factors. DLC was deposited on stainless steel disks using an unbalanced magnetron sputtering system. Pure water and quasi-tap water, which imitates typical tap water sampled in Tokyo, were used to study the effects of dissolved ions. The water temperature was elevated from $20^{\circ} \mathrm{C}$ to $80^{\circ} \mathrm{C}$. The results show that temperature as well as the dissolved ions have a major impact on friction and wear. More specifically, the coefficient of friction was increased at elevated temperatures. Also, in pure water, abrasive wear of DLC was observed due to aluminum condensation on the brass surface, whereas it was prevented in quasi-tap water since aluminum was removed from the contact region due to the dissolved ions. EPMA, XPS and AES indicated
\end{abstract}


that the tribo-layer on the metal surfaces, which consists of carbon and the base metal as well as some elements from water, plays an important role.

Key words: water lubrication; diamond-like carbon; brass; tribo-layer; surface characterization

\section{Introduction}

The development of water hydraulic systems using metal-based materials has been carried out as a national research project in Japan. Although water hydraulic systems made primarily from ceramics and plastics are commercially available at present, their use is limited because of high cost and inferior fracture toughness. The use of metal based-materials could improve and eliminate such difficulties.

The water to be used in these systems is tap water with no additives, for ease of use and drainage. In addition, the operating conditions of the water, such as the water temperature, water pressure, dissolved oxygen and dissolved ions, will vary depending on the machinery, plant, system, region etc. Thus, the developed system must be robust in a water environment.

Combinations of diamond-like carbon (DLC) vs. stainless steel and DLC vs. brass are expected to achieve low friction and wear under water lubricated conditions, for excellent tribological performance [1-4]. Researchers have studied the effects of the water environment on wear and friction of DLC rubbed against AISI 630 stainless steel, and they have shown that the water temperature and the dissolved ions have a significant impact on the phenomena [5]. Specifically, wear and friction increased at elevated temperatures especially in tap water environment. It was also found that that the tribo-layer on the steel surface, which is affected by the temperature and dissolved ions, plays an important role in inhibiting direct contact and subsequent wear by a degraded DLC top-layer and the wear debris [5]. The importance of the tribo-layer on the DLC counter surface has also been demonstrated in previous work [4, 6-9]. 
With regards to DLC vs. brass in a water-based environment, investigations by Ohana et al. and Yamamoto et al. have shown larger wear of the brass and higher friction than those of DLC vs. steel $[4,10]$. Also, these studies have shown that the wear of brass and friction are strongly affected by the hardness and surface roughness of the DLC. However, most studies related to water lubrication with DLC were conducted in pure water, and there are no previous reports on the tribological aspects of DLC vs. brass focusing on the temperature, dissolved ions etc. in a tap water environment, which is more realistic from an applications point of view.

This study therefore is aimed at clarifying the effects of the water environment on the tribological properties of DLC rubbed against brass.

\section{Experimental}

A ball-on-disk type rotating tribotester in an autoclave, which can be operated under a controlled water environment in terms of temperature $\left(20-80^{\circ} \mathrm{C}\right)$, water pressure $(0.1-20 \mathrm{MPa})$ and dissolved oxygen (0.01-8ppm), was used in this research (Fig. 1)[5]. The water temperature was controlled using a constant temperature bath as shown in Fig. 1. The water pressure and the amount of dissolved oxygen were controlled with a high pressure pump and $\mathrm{N}_{2}$ and $\mathrm{N}_{2}+\mathrm{O}_{2}$ gas aeration, respectively.

A DLC coating with $1 \mu \mathrm{m}$ thickness was applied on H900 hardened AISI 630 stainless steel disks (Fe-17Cr-4Ni-4Cu) by an unbalanced magnetron sputtering system [4]. The measured nano-indentation hardness of the DLC coating was $16 \mathrm{GPa}$. More details on the coating can be found in Refs. [4, 5]. The balls were made of type P31CHL high tensile brass (Cu-26Zn-3Al-2Ni) $9.5 \mathrm{~mm}$ in diameter. The hardness of the ball material was HV 500 (4.9 GPa). The surface roughness of both specimens was $0.03 \mu \mathrm{m}$ in Ra.

Quasi-tap water, imitating typical tap water sampled in Tokyo, was prepared and used for the experiment. The properties of the quasi-tap water are listed in Table 1. Pure water de-ionized with an ion-exchange resin was also used for comparison. 
Experiments were carried out in two steps. The screening of environmental factors was conducted first using an L9 orthogonal table as shown in Table 2. The normal load was also varied as indicated in Table 2. In this L9 experiment, the number of repetition is one. Then, a detailed examination of varying the temperature and the dissolved ions, which were found to be significant for wear in the L9 experiment, was conducted according to the experimental conditions shown in Table 3. The experiment was conducted twice at each condition.

The wear volume of the DLC disk was calculated from wear scar profiles obtained with a stylus profilometer. An optical microscope was employed to estimate the wear volume of the ball specimen under the assumption that the wear scar is flat. Scanning electron microscopy (SEM), electron probe micro analysis (EPMA), Auger electron spectroscopy (AES) and X-ray photoelectron spectroscopy (XPS) were employed for surface characterization of the specimens.

\section{Results}

Figure 2 shows the results of the L9 experiment. It can be seen that the temperature strongly affects the wear of the DLC. In addition, the wear rate of the brass ball decreased with an increase in the load probably due to topographical change of the ball specimens, i.e., the actual contact pressure decreases with flattening of the balls [4]. It can also be observed that the wear of the brass ball is much smaller in a pure water environment.

Figure 3 shows the specific wear rate of the DLC disks at various water temperatures and load conditions, as shown in Table 3. The average of coefficients of variation in pure water and quasi-tap water at each condition were $30 \%$ and $20 \%$, respectively. It can be seen that the wear of the DLC increased with increasing temperature. In addition, the wear of the DLC is larger in a pure water environment compared to that in quasi-tap water. These results are consistent with those of the L9 experiment.

Changes in the coefficient of friction as a function of time in various water environments are shown in Fig. 4. At first, the friction decreased as a function of the sliding distance for all cases. 
However, at $80{ }^{\circ} \mathrm{C}$, the friction increased after a sliding distance of $200 \mathrm{~m}$, different from that of the case at $20^{\circ} \mathrm{C}$.

Figures 5 and 6 compare the morphologies of the DLC wear scars in different water environments. As can be seen, the wear scar in pure water shows deep and severe scratches, whereas the scar in the quasi-tap water shows a wide and shallow profile with a smaller number of scratches. Since the depth of the scratches $(\sim 600 \mathrm{~nm})$ is less than the coating thickness $(1 \mu \mathrm{m})$, contact between the brass and stainless steel substrate has not occurred.

Figure 7 shows SEM images and the corresponding EPMA images of the brass wear scars in the two environments. In pure water, as shown in Fig. 7(a), condensation of aluminum is seen on the wear scar, whereas in the quasi-tap water, aluminum accumulates on the backside of the wear scar, as shown in Fig. 7(b)-region A. Oxygen and a small amount of carbon are also found on the wear scars for both tribo-surfaces. AES depth profiles of the brass wear scars shown in Fig. 8 also demonstrate condensation of aluminum in the wear scar in pure water. Carbon from the DLC is present in the tribo-layer with a thickness of about $500 \mathrm{~nm}$ or more in both pure water and quasi-tap water. With regards to the elements from the quasi-tap water, calcium and magnesium were found in the tribo-layer in, as shown in Fig. 8(b). Figure 9 compares the morphologies of the tribo-layer on the brass surfaces formed at different temperatures in quasi-tap water. At $20{ }^{\circ} \mathrm{C}$, a thick tribo-layer with a mud-crack structure was obtained. Localized AES analysis revealed that the part with the mud-crack in Fig. 9(a) contains a fair amount of calcium and magnesium, as shown in Fig. 8(b). The tribo-layer at $80{ }^{\circ} \mathrm{C}$ (Fig. 9(b)) also contained calcium and magnesium, however, it was rather thin and heterogeneous. Figure 10 shows the compliance curves of the tribo-layer obtained in quasi-tap water at $20{ }^{\circ} \mathrm{C}$. Since the layer becomes softer in water, it can be assumed that the tribo-layer is gel-like. The mud-crack structure shown in Fig. 9(a) was probably formed when the specimen was desiccated for SEM observations. As for the chemical composition of the DLC surfaces, no notable change was observed. 


\section{Discussion}

\subsection{Effects of dissolved ions}

As shown in Figs. 5 and 6, the DLC was worn in an abrasive mode in pure water. However, abrasion was inhibited in the quasi-tap water environment. The aluminum oxide on the brass counter surface, as shown in Figs. 7(a) and 8(a), is likely responsible for this, i.e., hard aluminum oxide can abrade DLC surface $[8,14]$. On the other hand, in quasi-tap water, aluminum accumulated on the backside of the wear scar on the brass ball, not within the wear scar (Fig. 7(b)). The amount of dissolved ions is small $(0.14 \mathrm{mg} / \mathrm{l}$ in total $)$, however, its effect is not negligible. The following is a possible explanation for this process.

When a fresh surface of metals is exposed by rubbing, a local cell is created [11-13]. Then, metal is ionized and dissolves into water. The possible process for this is illustrated in Fig. 11. Aluminum can be selectively ionized because it has the lowest standard potential $(\mathrm{Cu}: 0.337 \mathrm{~V}$, $\mathrm{Ni}:-0.250 \mathrm{~V}, \mathrm{Zn}:-0.763 \mathrm{~V}, \mathrm{Al}:-1.66 \mathrm{~V})$, which means that it is the easiest to be ionized [15]. The dissolved aluminum releases electrons as follows.

$$
\mathrm{Al} \rightarrow \mathrm{Al}^{3+}+3 \mathrm{e}^{-}
$$

The released electrons are used to produce $\mathrm{OH}^{-}$, and $\mathrm{Al}^{3+}$ then accumulates outside of the wear scar, which is cathodic, after being trapped by the $\mathrm{OH}^{-}$.

$$
1 / 2 \cdot \mathrm{O}_{2}+\mathrm{H}_{2} \mathrm{O}+2 \mathrm{e}^{-} \rightarrow 2 \mathrm{OH}^{-}
$$

$$
\mathrm{Al}^{3+}+3 \mathrm{OH}^{-} \rightarrow \mathrm{Al}\left(\mathrm{OH}^{-}\right)_{3}
$$

The $\mathrm{Al}\left(\mathrm{OH}^{-}\right)_{3}$ produced will be accumulated on the backside of the brass wear scar because of the 
movement of the fluid, which is consistent with Fig. 7(b). This kind of phenomenon is called "parting" or "selective dissolution", and is known to occur in copper-alloy containing aluminum, CoCrMo alloy etc. $[15,16]$. This process will be drastically accelerated compared to static corrosion due to exposure of a fresh surface by the mechanical action.

This process is possible only when all the reactions shown above proceed simultaneously, i.e., ionization of aluminum does not occur just by itself. The second step, the production of $\mathrm{OH}^{-}$, does not easily occur in pure water because of the extremely low electrical conductivity of pure water $\left(\leq 0.09 \mathrm{mS} / \mathrm{m}\right.$ which is less than $(1 / 300)^{\text {th }}$ of that in quasi-tap water) [17]. Once the remaining aluminum is oxidized and embedded as hard particles on the brass surface, it will be difficult to remove these and will continue abrading the DLC surface. The smaller wear of brass in pure water shown in Fig. 2 is responsible for this layer which works as a protective layer for brass. This assumption suggests that attentions must be paid to the tribo-electrochemical aspects for selection of a metal in water lubrication.

Another possible mechanism for prohibiting of aluminum condensation in quasi-tap water is the formation of a tribo-layer which makes aluminum removal easier. However, as for now, the authors have found no evidence to support this idea.

\subsection{Effect of temperature}

The wear of DLC increased with increasing temperature, which is consistent with the results obtained in previous research in Refs. $[6,8,9,14]$, which were conducted in various environments. As shown in Figs. 9 (a) and 10, an intact and lubricious tribo-layer was formed at 20 ${ }^{\circ} \mathrm{C}$. However, the growth of this layer was suppressed at $80{ }^{\circ} \mathrm{C}$ (Fig. 9(b)). The frictional behavior, showing a gradual decrease in the first stage (Fig.4), likely corresponds to the growth of the tribo-layer as well as topographical run-in. The increase in friction after $100 \mathrm{~m}$ of sliding is probably due to the temperature rise at the contact interface by frictional heat generation and surrounding temperature. To support this idea, additional experiments were carried out at a 
decreased speed. Figure 12 shows the average coefficient of friction at steady state at a lower sliding speed of $0.04 \mathrm{~m} / \mathrm{s}$. Friction did not increase with an increase in the water temperature when the sliding speed was lower, i.e., frictional heat generation is smaller. SEM observations revealed that a tribo-layer was successfully formed when the sliding speed was lower even at $80{ }^{\circ} \mathrm{C}$. Hence, it can be stated that a higher temperature at the contact interface makes it difficult to form a beneficial tribo-layer. Once direct contact between the brass and DLC occurs, the friction and wear will increase [7]. Increased friction would make the contact temperature higher and makes beneficial tribo-layer formation more difficult. Thus, the tribological properties spiral into a vicious circle due to the elevated temperature and frictional heat generation. This also suggests that it is not necessarily 50 or $80{ }^{\circ} \mathrm{C}$ at which inferior tribo-performance is seen. If the contact temperature is elevated by increased sliding speed, lower thermal diffusivity etc., the tribo-performance will suffer even at lower temperatures. The lack of a lubricious tribo-layer causes more frequent direct contact between the metal and DLC and results in higher friction and wear [18]. More frequent direct contact may promote the degradation of the DLC top-layer by larger frictional heat generation $[9,19]$ and result in larger wear of the DLC.

\section{Conclusion}

In this paper, the tribological properties of DLC rubbed against high tensile brass in various water environments were studied. Wear and frictional behavior of DLC rubbed against brass in water are affected by the water temperature and dissolved ions. Specifically, elevated temperature and frictional heat generation prevent the formation of intact and lubricious tribo-layer resulting in higher friction and wear. Aluminum oxide condensation on the brass surface was seen in pure water and caused severe abrasive wear of the DLC. Dissolved ions prevented this by removing aluminum from the brass wear scar. One possible reason for this is electrochemical selective 
dissolution from exposed fresh surface formed by the rubbing.

\section{Acknowledgements}

This work was performed as part of the Japanese national research project on Smart Materials for

Tribo-Systems in Drive Units and was supported by NEDO.

\section{References}

[1] T. Ohana, T. Nakamura, M. Suzuki, A. Tanaka and Y. Koga, "Tribological Properties and Characterization of DLC Films Deposited by Pulsed Bias CVD", Diamond and Related Materials, 13, (2004) 1500-1504.

[2] T. Ohana, M. Suzuki, T. Nakamura, A. Tanaka and Y. Koga, "Low-Friction Behaviour of Diamond-like Carbon Films in a Water Environment", Diamond and Related Materials, 15, (2006) 962-966.

[3] T. Ohana, M. Suzuki, T. Nakamura, A. Tanaka and Y. Koga, "Tribological Properties of DLC Films Deposited on Steel Substrate with Various Surface Roughness", Diamond and Related Materials, 13, (2004) 2211-2215.

[4] K. Yamamoto and K. Matsukado, "Effect of Hydrogenated DLC Coating Hardness on the Tribological Properties under Water Lubrication", Tribology International, 39, (2006) 1609-1614.

[5] M. Uchidate, H. Liu, A. Iwabuchi, and K. Yamamoto, "Effects of Water Environment on Tribological Properties of DLC Rubbed against Stainless Steel", Wear, 263, (2007)1335-1340.

[6] A. Erdemir and G.R. Fenske, "Tribological Performance of Diamond and Diamondlike Carbon Films at Elevated Temperatures", Tribology Transactions, 39, 4, (1996) 787-794.

[7] H. Ronkainen, S. Varjus and K. Holmberg, "Friction and Wear Properties in Dry, Water- and Oil-Lubricated DLC against Alumina and DLC against Steel Contacts", Wear, 222, (1998) $120-128$. 
[8] E. Konca, Y. -T. Cheng, A. M. Weiner, J. M. Dasch and, A. T. Alpas, "Elevated temperature tribological behavior of non-hydrogenated diamond-like carbon coatings against 319 aluminum alloy",Surface \& Coating Technology, 200, (2006) 3996-4005.

[9] A. Vanhulsel, B. Blanpain, J.-P. Celis, J. Roos, E. Dekempeneer and J. Smeets, "Study of the Wear Behavior of Diamond-Like Coatings at Elevated Temperatures", Surface and Coating Technology, 98 (1998) 1047-1052.

[10] T. Ohana, M. Suzuki, T. Nakamura, A. Tanaka and Y. Koga, "Tribological Properties of DLC Films Deposited on Steel Substrate with Various Surface Roughness", Diamond and Related Materials, 13, (2004) 2211-2215.

[11] A. Iwabuchi, T. Sonoda, H. Yashiro and T. Shimizu, "Application of Potential Pulse Method to the Corrosion Behavior of the Fresh Surface Formed by Scratching and Sliding in Corrosive Wear", Wear, 225-229 (1999) 181-189.

[12] A. Iwabuchi, M. Uchidate, H. Liu, T. Miura and T. Shimizu, "The Effect of Dissolved Ions on Tribological Properties in Water", Life Cycle Tribology (Proceedings of the 31st Leed-Lyon Symposium on Tribology), (2005) 431-440.

[13] S. Mischler and P. Ponthiaux, "A Round Robin on Combined Electrochemical and Friction Tests on Alumina/Stainless Steel Contacts in Sulphuric Acid", Wear, 248 (2001) 211-225.

[14] W. Ni, Y.-T. Cheng, A.M. Weiner and T.A. Perry, "Tribological Behavior of Diamond-Like-Carbon (DLC) Coatings against Aluminum Alloys at Elevated Temperatures", Surface and Coating Technology, 201 (2006) 3229-3234.

[15] H. H. Uhlig, Corrosion and Corrosion Control: An Introduction to Corrosion Science and Engineering: Third Edition, Wiley-Interscience, (1985) 332-334.

[16] A. W. E. Hodgson, S. Kurz, S. Virtanen, V. Fervel, C.-O.A. Olsson and S. Mischler, "Passive and transpassive behavior of CoCrMo in simulated biological solutions", Electrochimica Acta, 49, (2004) 2167-2178.

[17] A. Iwabuchi, J. W. Lee and M. Uchidate, "Synergistic effect of fretting wear and sliding wear of 
Co-alloy and Ti-alloy in Hank's solution", Wear 263 (2007) 492-500.

[18] H. Li, T. Xu, C. Wang, J. Chen, H. Zhou and H. Liu, "Friction-induced physical and chemical interactions among diamond-like carbon film, steel ball and water and/or oxygen molecules", Diamond Related Materials, 15 (2006) 1228-1234.

[19] C. Ziebert, M. Rinke, M. Stuber, S. Ulrich and H. Holleck, "Interfaces and temperature stability of stepwise graded DLC films studied by nanoindentation and Raman spectroscopy", Surface and Coatings Technology, 200 (2005) 1127-1131. 


\section{List of Tables}

Table 1 Details of typical tap water in Tokyo and quasi-tap water in Tokyo

Table 2 L9 orthogonal table for examination of environmental factors and load

Table 3 Experimental conditions for detailed examination of temperature and dissolved ions 


\section{List of Figures}

Fig. 1 Schematic diagram of the tribotester used in this study.

Fig. 2 Wear results of the L9 experiment.

Fig. 3 Specific wear rate of the DLC disks

Fig. 4 Friction behavior in various water environments.

Fig. 5 Wear scar profiles of the DLC disks (load $\left.57 \mathrm{~N}, 80{ }^{\circ} \mathrm{C}\right)$

Fig. 6 SEM images of the DLC wear scars $\left(\operatorname{load} 57 \mathrm{~N}, 80{ }^{\circ} \mathrm{C}\right)$

Fig. 7 SEM and EPMA images of the wear scars formed on the brass balls rubbed against the DLC disks (load $\left.30 \mathrm{~N}, 80^{\circ} \mathrm{C}\right)$.

Fig. 8 AES depth profiles of the tribo-layer on brass balls (load $57 \mathrm{~N}, 80^{\circ} \mathrm{C}$ ).

Fig. 9 SEM images of the brass surface rubbed in quasi-tap water at different temperatures (load $57 \mathrm{~N})$.

Fig. 10 Compliance curves of the tribo-layer on the brass surface formed in quasi-tap water $\left(20^{\circ} \mathrm{C}\right)$.

Fig. 11 Schematic diagram of the dissolution and accumulation of aluminum hydroxide.

Fig. 12 Effects of sliding speed on friction. 
Table 1

\begin{tabular}{lccc}
\hline & & $\begin{array}{c}\text { Tap water } \\
\text { sampled } \\
\text { in Tokyo }\end{array}$ & $\begin{array}{c}\text { Quasi-tap } \\
\text { water }\end{array}$ \\
\hline $\begin{array}{l}\text { Dissolved ions } \\
(\mathrm{mg} / \mathrm{l})\end{array}$ & $\mathrm{Cl}^{-}$ & 30 & 31 \\
& $\mathrm{NO}_{3}{ }^{-}$ & 12 & 13 \\
& $\mathrm{SO}_{4}{ }^{2}$ & 36 & 37 \\
& $\mathrm{Na}^{+}$ & 22 & 24 \\
& $\mathrm{~K}^{+}$ & 2.8 & 2.5 \\
$\mathrm{Mg}^{2+}$ & 5.0 & 5.3 \\
Electrical & $\mathrm{Ca}^{2+}$ & 22 & 23 \\
conductivity $(\mathrm{mS} / \mathrm{m})$ & 28.9 & 29.4 \\
pH & & $7.2-7.8$ & $7.4-7.9$ \\
\hline
\end{tabular}


Table 2

\begin{tabular}{ccccc}
\hline $\begin{array}{c}\text { Exp. } \\
\text { no. }\end{array}$ & $\begin{array}{c}\text { Load } \\
{[\mathrm{N}]}\end{array}$ & $\begin{array}{c}\text { Temper- } \\
\text { ature } \\
{\left[{ }^{\circ} \mathrm{C}\right]}\end{array}$ & $\begin{array}{c}\text { Dissolved } \\
\text { oxygen } \\
{[\mathrm{ppm}]}\end{array}$ & $\begin{array}{c}\text { Water } \\
\text { pressure } \\
{[\mathrm{MPa}]}\end{array}$ \\
\hline 1 & 10 & 20 & 0.01 & 0.1 \\
2 & 10 & 50 & 0.1 & 1.0 \\
3 & 10 & 80 & 7 & 19 \\
4 & 30 & 20 & 0.1 & 19 \\
5 & 30 & 50 & 7 & 0.1 \\
6 & 30 & 80 & 0.01 & 1.0 \\
7 & 57 & 20 & 7 & 1.0 \\
8 & 57 & 50 & 0.01 & 19 \\
9 & 57 & 80 & 0.1 & 0.1 \\
\hline
\end{tabular}


Table 3

\begin{tabular}{cc}
\hline Turning speed & $0.4 \mathrm{~m} / \mathrm{s}$ \\
Load (on three balls) & $11,31,58 \mathrm{~N}$ \\
Number of revolutions & 36,000 (Approx) \\
Water pressure & $0.1 \mathrm{MPa}$ \\
Dissolved oxygen & $7-8 \mathrm{ppm}$ \\
Water temperature & $(20,50,80) \pm 2{ }^{\circ} \mathrm{C}$ \\
Water & Pure water, quasi-tap water \\
\hline
\end{tabular}




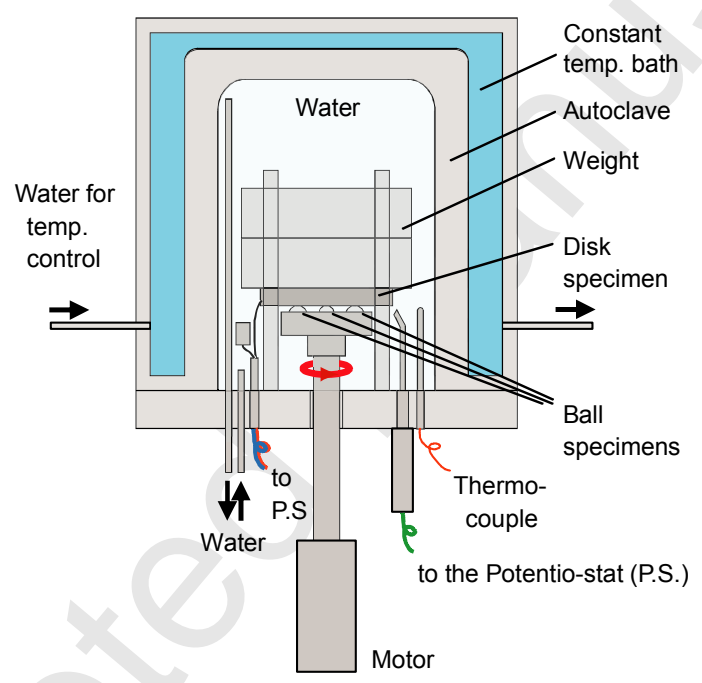

Fig. 1 


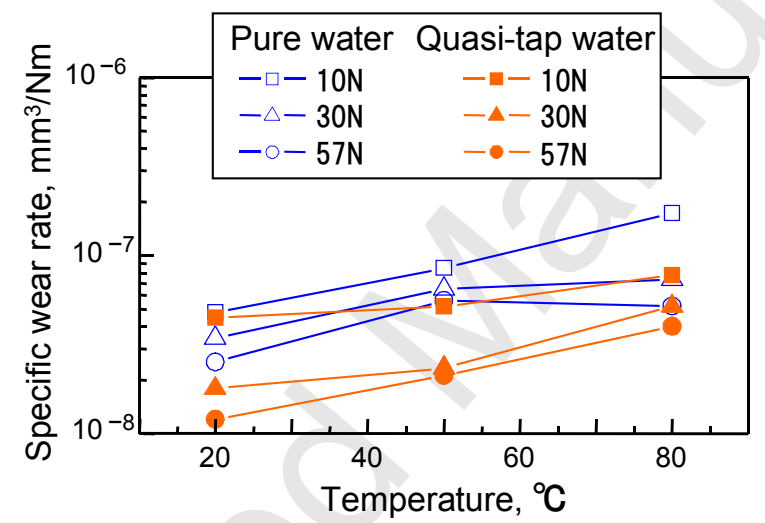

Fig. 3 


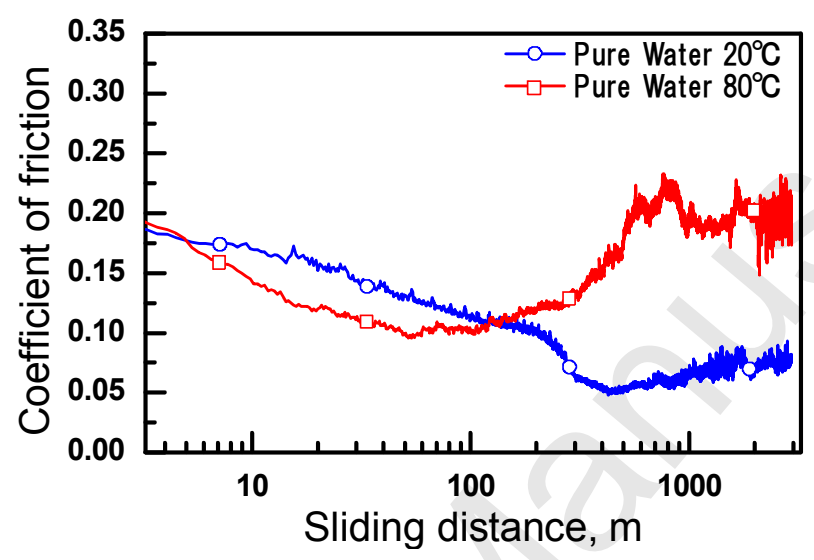

(a) In pure water

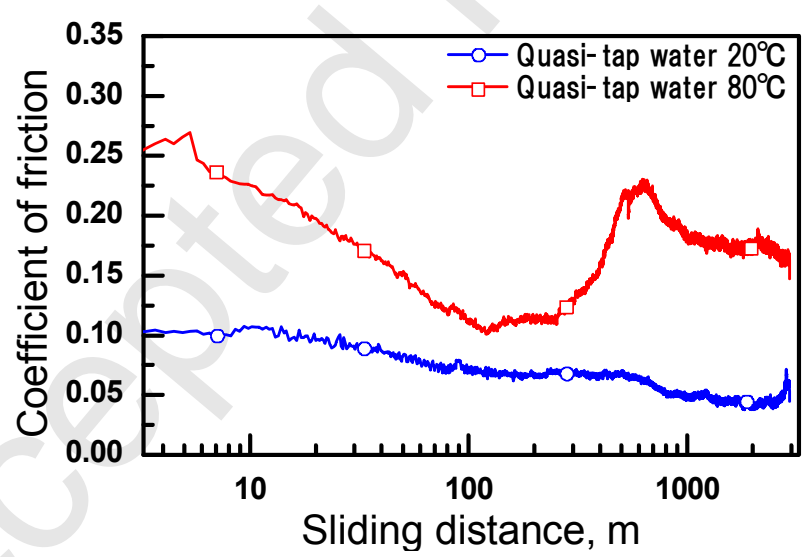

(b) In quasi-tap water

Fig. 4 
(a) In pure water

(b) In quasi-tap water

Fig. 5 


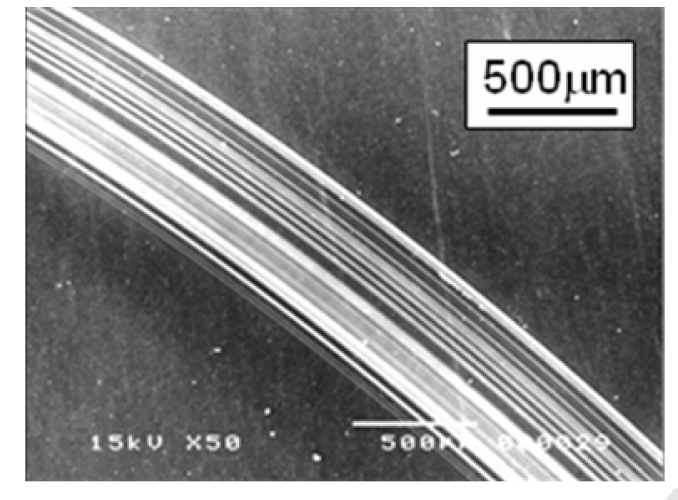

(a) In pure water

(a) In pure water

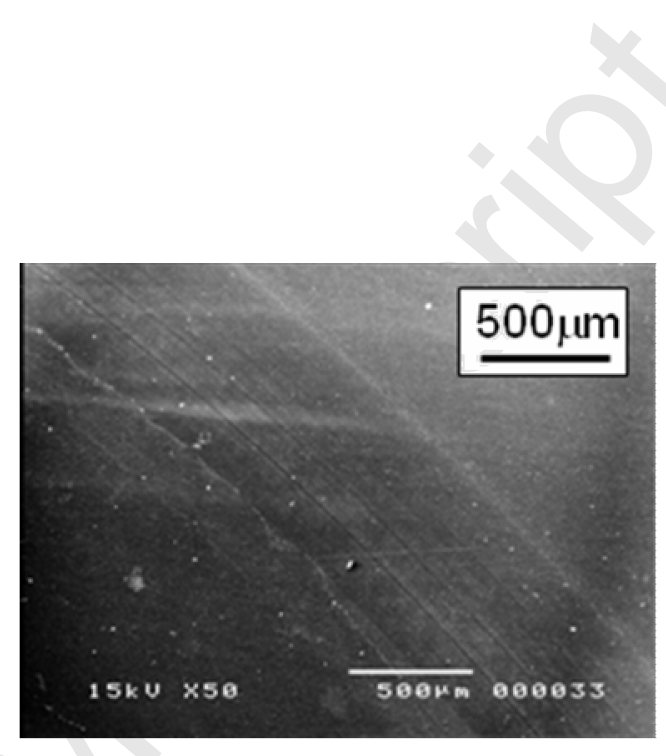

(b) In quasi-tap water

(b) In quasi-tap water

Fig. 6 


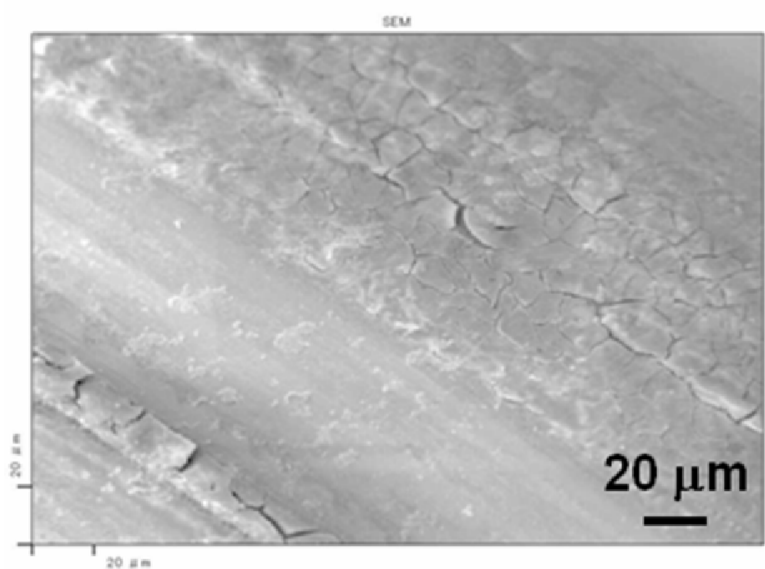

(a) $20^{\circ} \mathrm{C}$

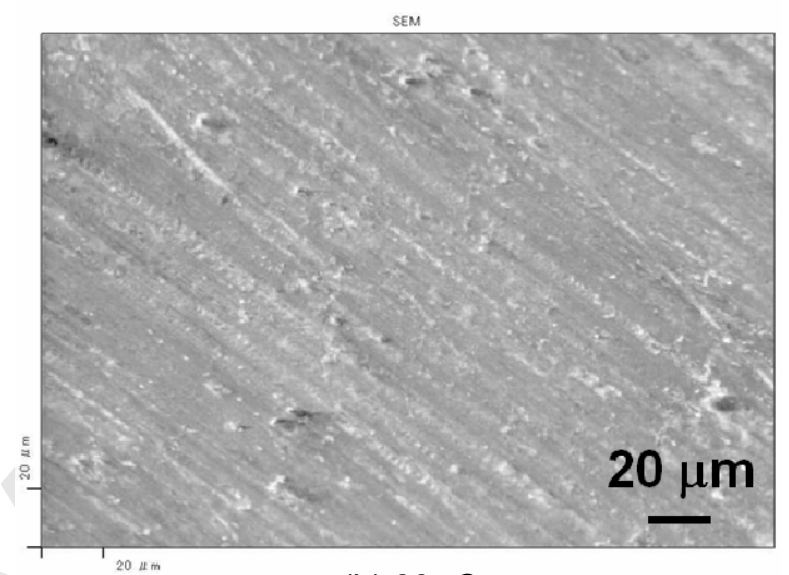

(b) $80^{\circ} \mathrm{C}$

Fig. 9 


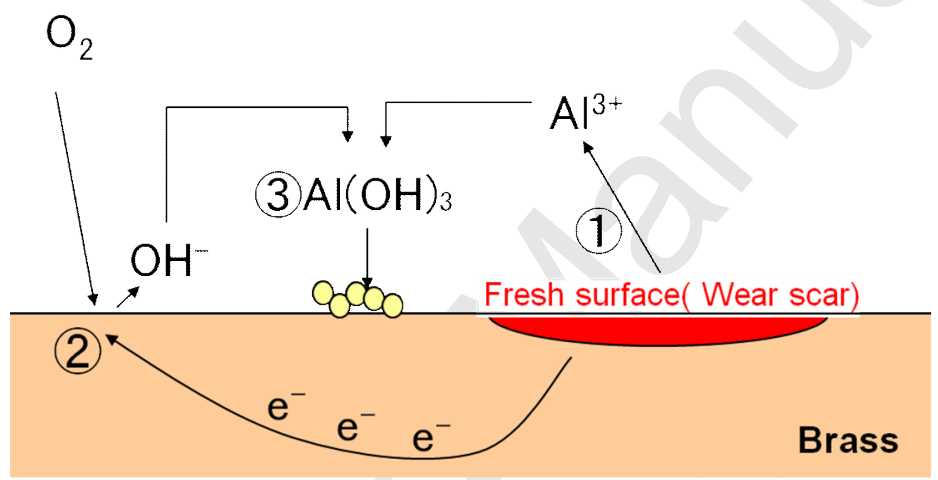

Fig. 11 


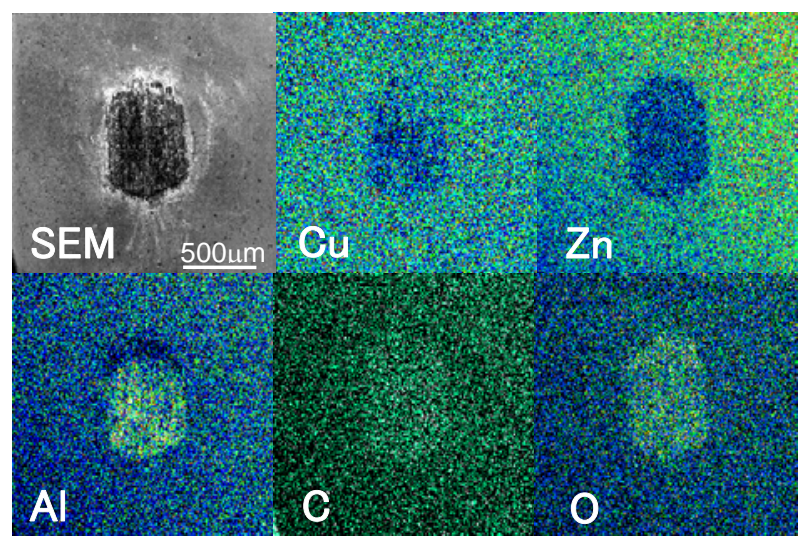

(a)In pure water

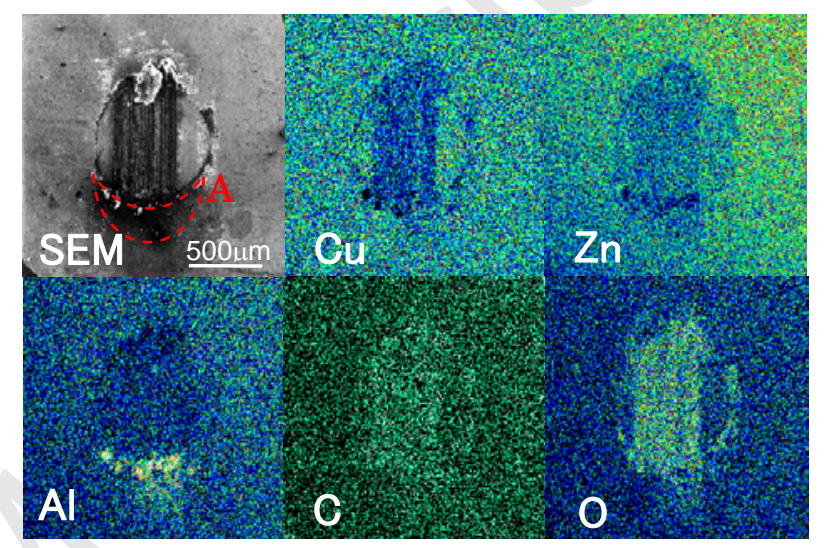

(b)In quasi-tap water

Fig. 7 

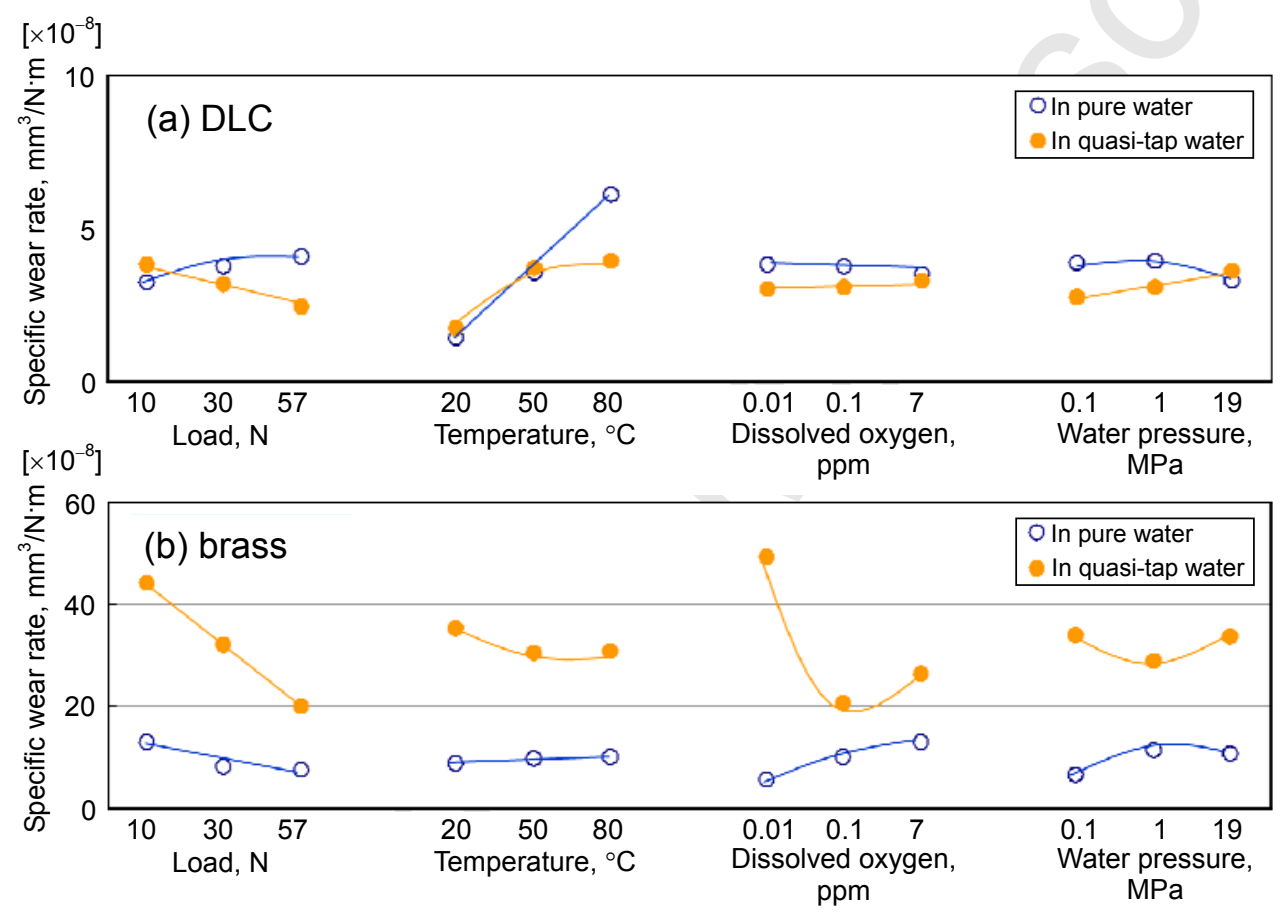

Fig. 2 


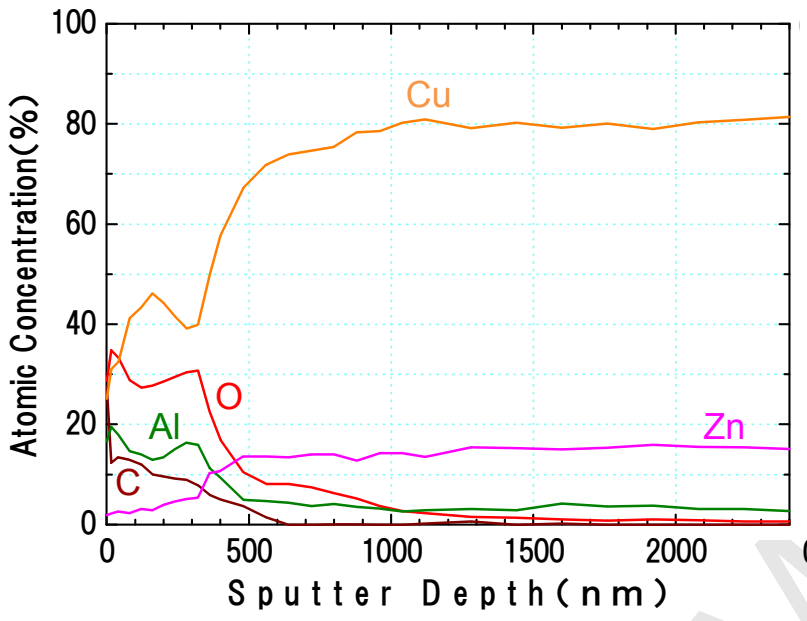

(a)In pure water

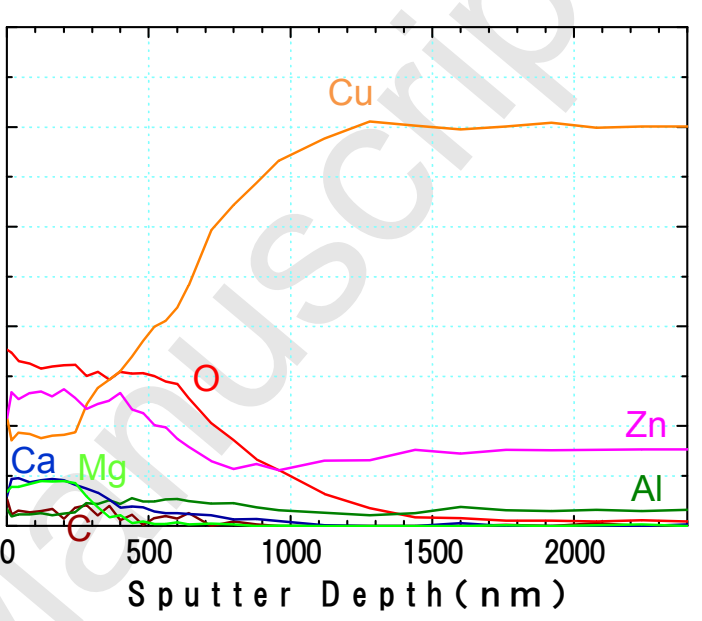

(b)In quasi-tap water

Fig. 8 


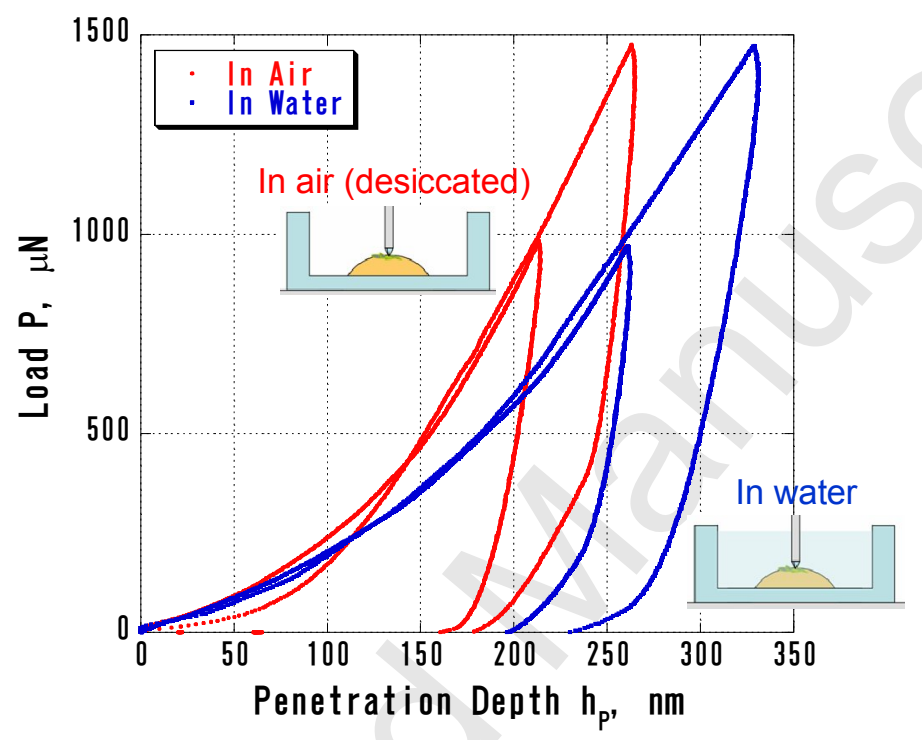

Fig. 10 


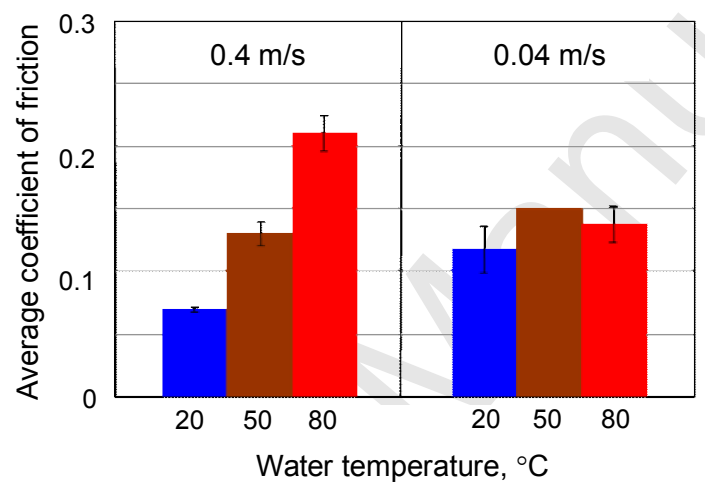

Fig. 12 